\title{
VÍNCULOS SUBJETIVOS DO AGENTE COMUNITÁRIO DE SAÚDE NO TERRITÓRIO DA ESTRATÉGIA SAÚDE DA FAMÍLIA
}

\author{
SUBJECTIVE BONDS OF THE COMMUNITY HEALTH AGENT IN \\ THE TERRITORY OF THE FAMILY HEALTH STRATEGY
}

\author{
VÍNCULOS SUBJETIVOS DEL AGENTE COMUNITARIO DE SALUD EN EL \\ TERRITORIO DE LA ESTRATEGIA SALUD DE LA FAMILIA
}

\author{
Antonio Germane Alves Pinto ${ }^{1}$ \\ Maria Augusta Vasconcelos Palácioº \\ Aurylene Cordeiro Lôbo ${ }^{3}$ \\ Maria Salete Bessa Jorge ${ }^{4}$
}

Resumo Este estudo propõe apresentar as experiências no trabalho do agente comunitário de saúde integralizando as relações intersubjetivas no território. A vinculação com a comunidade advém da sua implicação com as mesmas dificuldades da população que acompanha. Objetiva-se analisar as práticas cotidianas vivenciadas pelo agente comunitário de saúde no território da Estratégia Saúde da Família com ênfase nas relações comunitárias e os vínculos mantidos. Pesquisa com abordagem qualitativa em uma perspectiva crítico-reflexiva realizada no município de Fortaleza, estado do Ceará, de 2011 a 2013. Os participantes foram 11 agentes comunitários de saúde e 22 usuários de duas equipes da Estratégia Saúde da Família. Foram utilizadas como técnicas de coleta de dados a entrevista semiestruturada, a observação sistemática e o grupo focal. Os dados foram analisados sob os pressupostos da hermenêutica crítica. Os resultados evidenciam que, no cotidiano de trabalho do agente comunitário de saúde, as relações para o cuidado e promoção da saúde mantêm vínculos e afetos nos enfrentamentos comunitários, demandas e necessidades comunitárias. A informação e comunicação pelo diálogo dão sentido e significado às práticas de saúde e melhoria da qualidade de vida. Considera-se que os vínculos entre os usuários e agentes comunitários de saúde são potentes e resolutivos.

Palavras-chave agente comunitário de saúde; saúde da família; atenção primária à saúde; relações profissional-paciente.
Abstract This study proposes to present the experiences in the work of the community health agent that integrate the intersubjective relations in the territory. Their bonds with the community come from their involvement with the same difficulties the population they attend faces. The goal was to analyze the daily practices the community health agent experiences in the Family Health Strategy territory, with emphasis on community relations and on the bonds that are maintained. This study's approach involved a qualitative critical-reflective perspective carried out in the city of Fortaleza, state of Ceará, Brazil, from 2011 to 2013. Eleven community health agents and 22 users of two Family Health Strategy teams participated. Semi-structured interviews, systematic observation, and focus groups were used as data collection techniques. The data were analyzed under the assumptions of critical hermeneutics. The results show that, in the community health agent's daily work, the relationships for health care and promotion have ties and affection in community struggles, demands, and in community needs. Information and communication through dialogue give sense and meaning to health practices and improve quality of life. The bonds between users and community health agents are considered powerful and resolutive. Keywords community health agent; family health; primary health care; professional-patient relationships. 


\section{Introdução}

No cotidiano da Estratégia Saúde da Família (ESF), a contextualidade comunitária é permeada por relações e vínculos interpessoais. A convivência entre as famílias, vizinhos e comunidade em geral desvelam peculiaridades afetivas, solidárias e cuidadoras. As atitudes de pessoas nas ruas, vilas e lugares de moradia tendem a compor uma rotina de cooperação mútua, compartilhamento de sentimentos e expressividade da ajuda.

Nesse contexto, protagoniza-se a experiência de trabalho do agente comunitário de saúde (ACS) em integralizar a aproximação intersubjetiva. A vinculação deste profissional com a comunidade advém da sua implicação com as mesmas dificuldades da população que acompanha. As competências e habilidade técnica, assistencial e promocionista se aliam à sua condição horizontal para reconhecer as singularidades da vida comunitária (Cardoso e Nascimento, 2010; De Carli et al., 2014).

A adoção do enfoque da Atenção Primária à Saúde (APS) como modelo reordenador dos sistemas de saúde no Brasil e em diversos países se consolida com destaque ao trabalho territorial do ACS. No processo histórico de construção de seu espaço laboral - anterior ao Programa e, atualmente, Estratégia Saúde da Família - delimitam-se as dimensões técnica (vigilância à saúde) e política (relações solidárias de transformação comunitária). Consensualmente, o trabalho do ACS é caracterizado como elo entre a comunidade e o sistema de saúde (Fonseca et al., 2012; Pereira e Oliveira, 2013).

Configurando-se como elo entre a comunidade e a ESF, o ACS guarda a particularidade de ter como principal eixo do seu trabalho as práticas de educação em saúde. Há uma complexidade nesta lida, pois a ação educativa em saúde exige uma habilidade na confluência de saberes da saúde e do campo social (Fonseca et al., 2013). O ACS se torna um potencial transformador e emancipatório no processo de reorientação do modelo assistencial de saúde, mas também das condições sociais de sua comunidade.

A construção da identidade do ACS envolve, portanto, muitas especificidades que se relacionam tanto ao papel que ele desempenha como trabalhador na equipe de saúde, como de morador da comunidade. Ao vínculo que se estabelece para além das relações sociais, há uma ampla interlocução subjetiva para o cuidado em saúde. No envolvimento com as pessoas, os encontros desencadeiam tristezas e alegrias (Galavote et al., 2013), produzindo afetos e agenciamentos para a vida saudável.

O protagonismo do ACS se determina nas relações de trabalho, estabelecendo trocas entre saberes populares de saúde e saberes médico-científicos. Algo que pode indicar contradições, mas ao mesmo tempo promover diálogos, uma vez que o ACS veicula as práticas de saúde presentes na realidade onde mora e trabalha, mas é formado a partir dos referenciais biomédicos. 
Esse lugar ocupado pelo ACS distingue esse ator social como mediador entre a comunidade e a equipe de saúde (Bornstein e Stotz, 2008).

A mediação exercida pelo ACS extrapola os limites entre os conhecimentos popular e tecnocientífico. Com seus saberes e práticas, dinamiza o acesso da população ao serviço de saúde e aproxima as pessoas na construção de estratégias para melhoria da saúde e determinantes sociais da comunidade, com efetivas articulações e pactuações (Bornstein e Stotz, 2008). A amplitude laboral do ACS é constituída por um trabalho sustentado em relações assistenciais e de vínculo.

Operacionalmente, o processo de atuação territorial vislumbra a resolutividade de demandas e necessidades de saúde pelo cuidado operado na ESF. Entre os dispositivos ativadores de relações intersubjetivas, o vínculo decorre do acolhimento e requisita a responsabilização mútua entre as pessoas da equipe de saúde e os usuários do Sistema Único de Saúde (SUS) (Fracolli e Zoboli, 2004; Schimith e Lima, 2004; Jorge et al., 2011).

$\mathrm{O}$ vínculo como tecnologia relacional encontra no ACS um pilar para a sua construção, uma vez que este está mais próximo da realidade vivenciada pelas pessoas. O estabelecimento de vínculo permite que o outro possa usufruir da sua condição de sujeito ativo nas decisões acerca da sua vida. Torna-se um dispositivo potencializado pelo encontro subjetivo de trabalhadores e usuários, favorecendo a troca de experiências e possibilitando a construção de atos terapêuticos corresponsabilizados (Santos et. al., 2008; Lanzoni et al., 2013).

Destarte, como mantenedores ativos do vínculo com a comunidade, os ACS criam condições para estimular a autonomia dos usuários, pois estes, a partir do apoio que recebem do ACS, terão múltiplas possibilidades para superação dos seus problemas, bem como na amplitude decisória para práticas saudáveis (Viegas e Pena, 2012).

Nesse sentido, objetiva-se analisar as práticas cotidianas vivenciadas pelo ACS no território da ESF com ênfase nas relações comunitárias e vínculos mantidos.

\section{Metodologia}

O caminho percorrido para o desenvolvimento deste estudo é orientado pela abordagem qualitativa em uma perspectiva crítico-reflexiva. A sua definição parte do entendimento de que a compreensão da realidade emerge da análise crítica dos processos, estruturas, percepções, produtos e resultados, ao articular a visão dos atores sociais com a possibilidade de transformação de seus contextos (Minayo, 2014). Apresenta-se, neste caso, um recorte empírico da pesquisa “Clínica na Estratégia Saúde da Família: saberes, práticas e subjetividades" desenvolvida no período de março de 2011 a abril de 2013. 
Esta pesquisa foi realizada no município de Fortaleza, capital do estado do Ceará. A cidade tem uma população de 2.452.185 habitantes (Instituto Brasileiro de Geografia e Estatística, 2013). No âmbito municipal, os distritos sanitários são divididos pelas seis áreas administrativas das Secretarias Executivas Regionais (SER). As duas equipes selecionadas atuam nas SER IV e V. Tal escolha se justifica pela pactuação institucional da Universidade Estadual do Ceará com o Sistema Municipal Saúde-Escola da Secretaria Municipal de Saúde de Fortaleza em desenvolver estudos, pesquisas e parcerias de educação permanente nas referidas áreas.

A rede assistencial de atenção básica do município disponibiliza 255 equipes implantadas da ESF, perfazendo uma cobertura estimada do território de 35,88\% (Brasil, 2012b). A escolha das unidades de saúde foi delimitada pela gestão local dos distritos sanitários e a opção pela equipe ocorreu pela composição completa de seus membros e disponibilidade para participar da pesquisa.

Os participantes foram 11 ACSs atuantes no território da ESF, selecionados no desenvolvimento da pesquisa pela disponibilidade em realizar aproximação territorial em companhia do pesquisador. Ainda participaram 22 usuários visitados pelos ACSs. A composição da amostra final se respalda na saturação teórica (Flick, 2009).

No decurso da coleta dos dados, utilizaram-se as técnicas da entrevista semiestruturada, observação sistemática e grupo focal. A questão condutora das técnicas pautou a relação do ACS com os usuários, reciprocamente. De modo transversal, incidiu o enfoque sobre a ESF, em sua atuação preventiva e assistencial no território.

A partir da disponibilidade em participar da pesquisa, a realização da coleta de dados foi autorizada pela assinatura do termo de consentimento livre e esclarecido. Desse modo, cumpriu-se a recomendação ética da pesquisa envolvendo seres humanos (Brasil, 2012), sob respaldo do parecer n. 10724452-7 do Comitê de Ética em Pesquisa da Universidade Estadual do Ceará.

Os dados foram analisados sob os pressupostos da hermenêutica crítica (Minayo, 2014). Após a organização e classificação das narrativas obtidas das transcrições e anotações ocorreu a categorização temática, que foi sistematizada pela análise das convergências, divergências, diferenças e complementaridades das sínteses significantes das narrativas. Os trechos são ilustrados com relevância para o sentido crítico e reflexivo e discutidos à luz da literatura.

A intenção compreensiva da análise se pautou no reconhecimento dos sujeitos em suas relações, contextos, significados e sentidos. Desvelaram-se nas categorias temáticas o cotidiano de relações sociais e afetivas entre a comunidade e o ACS, e o desafiante modo de trabalho do ACS, atravessado por enfrentamentos urbanos nas ações de vigilância à saúde e transversalizado por atos acolhedores, solidários e resolutivos. 


\section{Resultados}

No cotidiano de trabalho do ACS incidem expressões e atitudes significantes na vida familiar da comunidade. As atitudes e os diálogos para o cuidado e a promoção da saúde no território da ESF proporcionam o estabelecimento de vínculos entre as pessoas. São também interações entre os moradores da comunidade que dão sentido à vida, numa relação mútua, o cuidado se torna um atributo desta rede social.

Desse contexto, apresentam-se as narrativas expressas nas comunidades atendidas pela equipe da ESF. Cada expressão constitui elementos interpretativos da atenção clínica no espaço familiar. Nesses ambientes, o protagonismo do ACS emerge em cada situação vivenciada cotidianamente. Por afetos e solidariedade, a vinculação entre as pessoas é algo inerente ao convívio familiar nos seus enfrentamentos do espaço comunitário ou domiciliar:

É muito bom viver aqui. Apesar dos problemas que sempre vão ter, a gente se diverte, conversa e se dá até bem uns com os outros (Usuária, em sua residência).

A sorte aqui é que todo mundo ajuda. Os vizinhos todos vêm aqui me ajudar. Conversam com ele [referindo-se ao esposo acamado], me ajudam a dar a comida e a tirar de um lugar para o outro. E não posso nunca deixar de agradecer a ajuda dessa santa, [referindo-se à ACS] ela é uma filha para a gente. Ajuda demais. Nem sei como agradecer tanto (Usuária).

Converge nesse cotidiano o trabalho operacional do ACS que se dá no processo de cadastramento, registro e monitoramento das condições de saúde da população. Entretanto, concomitantemente, emergem diálogos e conversas dispostos pela convivência, proximidade e confiança da comunidade na atuação deste profissional:

Eu conto as minhas coisas para a agente de saúde e ela está ali com uma palavra de conforto. Ela ajuda na medida do possível. É uma relação muito boa com os Agentes que a gente tem (Usuários).

Tem coisas que acontece que eles só desabafam comigo (ACS).

Emerge uma potencialidade do vínculo com a comunidade que se distingue nos projetos terapêuticos e nas ações de promoção da saúde, tornando-se atributo significativo para as relações vivenciadas. Expressam-se as afetividades mútuas no processo de trabalho consonantes com a disponibilidade compreensiva da orientação e comunicação. A participação integral no cuidado é destacada pelos ACSs em suas atitudes dialógicas cotidianas: 
Tem problema que eu não tenho resposta. Não tenho, mas mesmo assim eu ainda passo lá porque a gente cria um vínculo muito grande (ACS).

Quando eu chego na porta, antes de tudo, já ganho um abraço. Sempre, sempre temos situações de fome e dificuldade dentro das casas que visitamos. Mas é como eles dizem, quando você vem aqui, eu já me sinto mais renovado (ACS).

Complementarmente, os desafios para o trabalho em saúde extrapolam as ações específicas das categorias profissionais pela complexidade e diversidade dos problemas, em suas causalidades e consequências. Atuar no território é estar vinculado também por incertezas da sobrevivência social; requisitando integração das ações de saúde com o contexto comunitário. Nas observações, foram vivenciadas situações de conversas sobre as alegrias vividas, momentos de felicidade, resultados positivos em exames ou avaliações satisfatórias da saúde.

Sob conhecimento da prevalência de doenças e agravos, o ACS reconhece situações de risco à saúde das pessoas. Na interação com a comunidade, também se dialoga sobre recomendações para a saúde, quase sempre adequadas à realidade vivida pela comunidade:

A principal orientação é para os hábitos saudáveis. A gente sempre orienta para fazer caminhadas, se exercitar e evitar ficar parado demais. Varrer uma casa, limpar um quintal. Se mexer. Muitos problemas cardíacos são por conta desse jeito de ficar só parado, engordando (ACS).

A gente fala muito sobre alimentação. Tem gente que teima em comer coisa açucarada, sendo diabético; comida salgada, sendo hipertenso. Sem falar nas frituras! (ACS).

Com as mães das crianças a gente fala demais para ter cuidado com os alimentos. O risco de diarreia é grande. Limpar o quarto também para evitar muita poeira e os meninos griparem até ficar com pneumonia (ACS).

Complementam-se observações sobre as situações de interação com as pessoas, até mesmo em uso problemático de álcool e outras drogas, também enfatizadas sobre a resolutividade dos diálogos empreendidos:

O que mais chega para a gente é família passando por problemas com filho envolvido com as drogas. É um problema que mais a gente tem passado aqui na comunidade. Mexe com tudo. Os pais ficam apavorados. Os filhos não querem conversa. Mas a gente chega aos poucos. Sem julgar. Sem dizer nada. Apenas ouvindo. E a confiança é tão grande que eles se abrem com a gente. Dizem o que tão passando e quando dá 
a gente até encaminha ou arruma uma vaga para atendimento. É assim. Tem gente que se abre com a gente mais do que com a equipe no posto (ACS).

As atitudes do ACS se exemplificam na comunidade pela sua participação ativa na vida das pessoas de sua convivência:

A gente dá nosso exemplo participando da comunidade. Faço minha caminhada todo dia e mostro a eles que é bom para a saúde. Tudo é uma questão de vínculo. Aí é aonde que a gente vai descobrindo a dificuldade deles também (ACS).

Na convivência direta e horizontal com os usuários, os ACSs resgatam histórias de vida que dão àquelas pessoas a oportunidade de se tornarem sujeitos de seu tratamento. As narrativas enfatizam que, na busca por uma vida saudável, as prescrições são resultantes de consultas com interação reduzida ou ausente. Observa-se que os usuários, na saída dos consultórios, sempre expressam questionamentos sobre o modo de administrar um medicamento, a forma de agendar uma consulta especializada e as dificuldades quanto ao cumprimento das medidas de cuidado e prevenção de doenças.

Divergente do modo de trabalho do ACS, a relação estabelecida na lida assistencial pela equipe da ESF ainda se apresenta diretiva e afastada do componente relacional intersubjetivo. As narrativas destacam a reverência mantida durante a permanência na ESF e a busca por compreensão no ACS:

Eu não gosto de perguntar muito aos médicos. Eu nem entendo muito o que eles dizem. E também não gosto de perturbar. É tanta gente para atender. Deus me livre de perguntar! Eu pego a receita e pergunto [ao ACS] quando eu saio (Usuário).

A gente acaba tirando as dúvidas dos pacientes na comunidade. Aquilo que eles não entendem no posto (ACS).

Estrategicamente, a disponibilidade para informação e comunicação se torna uma permanente formação no trabalho do ACS. No incentivo para promoção da saúde comunitária, o trabalho educativo tem como resultado a participação social, o acesso ao cuidado e à atenção à saúde, bem como a melhoria das condições de vida da população:

Ele explica bem direitinho o que pode e o que não pode. Orienta. Tira dúvidas. Até de gente que não quer escutar. É muito bom contar com esse agente de saúde no bairro (Usuário).

A facilidade que eu, como agente de saúde, estou sempre correndo atrás é naquilo que está acontecendo atualmente. Seja na recepção, seja o que a enfermeira está fa- 
zendo, o que o médico está desenvolvendo, o que a coordenação está desenvolvendo. (...) A gente vai tentando captar tudo isso, através de quê? Da televisão, da internet, né? Dos meios de comunicação, que a gente tem disponível. E aí, eu corro atrás de tudo isso. A gente sabendo onde tem, nós vamos atrás. E repassa para a população (ACS).

Em momentos diferentes, as pessoas da comunidade oportunizam possibilidade de cuidado e promoção de saúde a partir do trabalho do ACS que atua como equipe da ESF, mas distintamente na sua condição de morador da comunidade. Compreendida no vínculo entre o ACS e a população, a resolutividade na assistência oferecida, seja na prevenção, promoção da saúde, cura ou reabilitação se estabelece em atos laborais, socioafetivos e solidários.

\section{Discussão}

Os diálogos operados no trabalho do ACS na comunidade são permeados pelas percepções sobre o que se vive e como se estabelecem os sentidos para as vidas, interpostos por condições e determinantes para a sobrevivência. Nas conversas entre a população e o representante da equipe da ESF, as pessoas exprimem seus sentimentos e disponibilizam suas vivências mais significativas para sua saúde.

Converge o acúmulo de experiência do ACS na comunidade e os vínculos mantidos com as pessoas no território que facilitam as ações de saúde empreendidas pela ESF. As práticas voltadas para a educação em saúde por meio das campanhas e prioridades de controle e prevenção são adicionadas por um potente elemento ativador de mudanças: a confiança entre o ACS e os usuários.

Quando a equipe de saúde reconhece que a ajuda de vizinhos, amigos e familiares é importante para o manejo cuidador, a efetividade do processo de cuidar se torna integralizado. Ao conter medidas terapêuticas aliadas à técnica profissional e às necessidades de apoio, acompanhamento clínico e conforto psicoemocional, as pessoas ativam entre si relações solidárias para manutenção do processo saúde-doença e torna possível a resolutividade assistencial (Fracolli e Zoboli, 2004; Pereira e Oliveira, 2013).

A vinculação das pessoas no bairro com suas necessidades e demandas de saúde apresenta-se no cotidiano com a consequente agregação de parcerias socioafetivas dispostas com o protagonismo do ACS. Como membro da equipe da ESF, o ACS opera com a habilidade específica de sua principal ferramenta assistencial: vínculos interpessoais (Cardoso e Nascimento, 2010).

Historicamente, os ACSs interpõem suas ações diárias no contexto das famílias pela aproximação social e afetiva que mantêm com todas as pessoas de seu convívio. $\mathrm{O}$ reconhecimento das necessidades sociais vividas pela população facilita ao ACS o controle e acompanhamento das condições de vida e saúde, mas eles também participam dos momentos de dificuldade com 
enfrentamento conjunto para além do registro de indicadores em si (Cardoso e Nascimento, 2010; Menegussi et al., 2014).

O trabalho do ACS compõe o processo de modificação da situação de saúde. Concomitantemente, as condições sociais da população brasileira vêm se modificando na última década pelo crescimento econômico e a inserção em programas sociais de repasse de renda aos grupos mais vulneráveis (Gomes e Pereira, 2005). Em sentido comum, o processo de consolidação da inclusão social requisita também superações sentidas e significadas pelas experiências e vivências com a miséria, sobrevivência e melhoria da qualidade de vida.

Intencionalmente, as práticas de educação em saúde objetivam o aprendizado das pessoas com ações que mantenham o nível de equilíbrio no processo saúde-doença. Na atenção à saúde, complementa-se com interações pedagógicas voltadas para a redução de danos à vida, sustentabilidade ambiental e participação popular em problemas e agravos do território (Ferreira Neto e Kind, 2010).

Nessa perspectiva, a facilidade que o vínculo ativo entre as pessoas proporciona para as práticas educativas na comunidade associa-se às iniciativas e experiências participativas e mobilizadoras para o entendimento das políticas públicas (Viegas e Penna, 2012). As conversas sobre o que é possível realizar pelo SUS conduzem para a compreensão dos usuários sobre seus direitos e deveres, nas relações assistenciais e também na conquista da cidadania.

O compromisso do ACS com os problemas da população gera uma relação de confiança que se pauta na expressão do compromisso profissional. As pessoas da comunidade percebem que o trabalho daquele profissional está voltado para a garantia dos direitos à saúde e a melhoria da qualidade de vida. Com gestos, escutas e conversas horizontais, a população incorpora, em sua maioria, as orientações terapêuticas e as recomendações para prevenção de doenças e promoção da saúde (Costa e Ferreira, 2011).

Eis a potência do vínculo comunitário para o pressuposto da Atenção Primária à Saúde: as relações interpessoais se tornam base para o trabalho voltado para a promoção da saúde (Gomes e Pinheiro, 2005). De modo singular, as visitas domiciliares e o acompanhamento direto na vida do território impulsionam naquelas pessoas que participam das ações na ESF a motivação necessária para modificar estilos de vida e hábitos pessoais que se relacionem com a saúde.

Exemplifica-se a ampliação da prática de saúde para relações intersubjetivas, com a dificuldade enfrentada pelos serviços de saúde na área da educação alimentar, atualmente reconhecida como adoção de práticas de ingestão adequada à necessidade calórica, diversidade de nutrientes e à qualidade dos alimentos. As propostas educativas são repassadas, mas a interpretação compreensiva e as condições para seguimento das recomendações reduzem a adoção das medidas protocolares sem resultado atitudinal pelas pessoas envolvidas (Caprara e Rodrigues, 2004).

É nesse contexto que a distância entre a intervenção didática pautada pelas regras protocolares e, por vezes, programáticas se chocam com a dispo- 
sição diferenciada do aprendizado coletivo; quase sempre, entre pessoas com escolaridade formal ausente ou diminuída. Nesse cruzamento entre o que é técnico, por um lado, e cultural, por outro, advém o trabalho do ACS que, por sua vinculação na ESF e na comunidade, facilita a linguagem empenhada nas campanhas e prioridades assistenciais.

É pela implicação social do ACS no território que a comunidade reconhece a possibilidade de parcerias e interações afetivas e emocionais ao compartilhar situações vividas (Jardim e Lancman, 2009). O vínculo necessário para a transposição da lógica preventivista das ações de saúde a uma perspectiva integrativa do cuidado e promoção da saúde se respalda no trabalho já empreendido pelo ACS nos territórios da ESF (De Carli et al., 2014).

É convergente a horizontalidade da fala do ACS nas conversas cotidianas com adolescentes e adultos sobre o uso de maconha, cocaína ou crack. Ao mesmo tempo, pauta na sua prática advertir as pessoas sobre o tabagismo com clareza e objetividade, o que demonstra a habilidade deste profissional em lidar com a responsabilidade técnica e a relação intersubjetiva que o afeto do vínculo exige.

Convém destacar que as abordagens terapêuticas voltadas para a população com problemas de utilização de drogas lícitas ou ilícitas que ocasionam situações de dependência química e desajuste social devem priorizar a composição psicossocial da vida humana. O adoecimento que se instaura no indivíduo e a deficiência em reconstruir suas relações sociais são os focos necessários para a recuperação e assistência integral em saúde mental (Fonseca et al., 2012).

De modo amplo, a equipe de saúde da família ainda recorre ao espaço território como área georreferenciada para cadastros e registros de vida e morbidade. O trabalho da ESF voltado para a operação da clínica na possibilidade de interagir de modo vinculado com os usuários apresenta lacunas e ausências de práticas integrativas (Caprara e Rodrigues, 2004; Favoreto, 2008; De Carli et al., 2014).

O trabalho do ACS nos domicílios deve estar em consonância com a atuação da equipe da ESF que convive acentuadamente na unidade de saúde, por dimensionar os usuários nas suas condições momentâneas ou crônicas de adoecimento ou perfil clínico. A relevância do diagnóstico ou da sintomatologia da população gera um distanciamento simbólico na relação equipe-usuário (Ayres, 2004). O vínculo entre a equipe e o usuário se converte em um atributo da prática clínica que torna o trabalho terapêutico mais confiante para ambos os sujeitos, e, para tanto, é preciso uma aproximação com o território (Lanzoni et al., 2013).

Os grupos de vulnerabilidade ou as populações de risco são dimensionados apenas na logística da informação e na análise dos dados epidemiológicos. A ampliação da relação clínica pode inserir atributos de compromisso, responsabilização e afetividade na sua operacionalidade. Obter estratégias para superar a estreita condição econômica e social significa aliar à clínica elementos que favoreçam o reconhecimento situacional da realidade vivida, no caso, o vínculo e a aproximação intersubjetiva (Ayres 2004; Pinto e Jorge, 2009; Viegas e Penna, 2012). 
Para a ampliação do potencial resolutivo da clínica, a operacionalidade que inclui o diálogo por meio de conversas sobre problemas do cotidiano favorece o reconhecimento também de causalidades e sintomatologias que possibilitem o diagnóstico preciso. As somatizações são resultantes de enfrentamentos circundantes à vida dos sujeitos, e a elucidação dessas dificuldades somente emerge de conversas entre quem se confia mutuamente (Schimith e Lima, 2004; Menegussi et al., 2014).

Em todas as situações vivenciadas na ESF, em decorrência da adoção da indicação unilateral, nem sempre compreendida por todos os usuários, a recuperação do processo saúde-doença se limita à remissão de sintomas gerais, sensíveis aos medicamentos ou procedimentos em si. A resolutividade assistencial integral resulta de projetos terapêuticos compartilhados horizontalmente com a interação de singularidades, subjetividades e objetivos comuns ao tratamento ou reabilitação: eis um caminho (Jorge et al., 2011; Backes et al., 2012).

Evidentemente, a vinculação que potencializa o cuidado em sua integralidade é a aproximação intersubjetiva e horizontal entre a equipe da ESF e os usuários. Especificamente, o que ocorre na comunidade é apenas o protagonismo do ACS na operação das práticas com vinculação, enquanto os demais membros da equipe absorvem apenas a lógica diretiva e objetivante da produção do cuidado (Santos e Assis, 2006; Jorge et al., 2011).

Para se produzir cuidado na dimensão intersubjetiva, ou seja, com interação horizontal e vinculada dos sujeitos equipe e usuário, se faz necessário admitir os limites e possibilidades de cada um na relação. Considerando o território em sua multiplicidade e na complexa rede social de condicionamento e determinação, emerge a ressignificação da prática clínica no trabalho do ACS. $\mathrm{O}$ vínculo que se forma na clínica é o que mantém ativo o processo de cuidado e desfaz obstáculos e entraves para a manutenção e promoção da saúde.

\section{Considerações finais}

Enfim, o vínculo emerge de atitude ética e estética da prática clínica e da convivência social. Na comunidade, o acompanhamento e controle em saúde que disparam interlocuções afetivo-emocionais e compartilhamentos psicossociais direcionam a clínica para um formato amplo e multidirecional. Nesse sentido, a clínica da ESF revela a atenção terapêutica pautada na diretividade, mas já inclui inovação tecnoassistencial na relação interposta entre ACS e usuários: vinculação.

Em todos os sentidos, a relação interpessoal vinculada apresenta possibilidades para a integralidade assistencial, tanto na dimensão biopatológica como na dimensão psicossocial. Na lida laboral do ACS, enquanto a equipe da ESF prioriza o tempo com o foco operacional na assistência ao usuário, este mantém permanente o reconhecimento de sujeitos no território pela vinculação e cuidado. 
Em síntese, os complexos problemas de saúde e demandas do território para a atenção à saúde no SUS exigem ações transversais às situações vivenciadas, bem como atitudes de aproximação, responsabilização e apoio terapêutico. Os vínculos entre usuários e ACS demonstram potentes e resolutivas trajetórias para os enfrentamentos cotidianos da ESF.

\section{Colaboradores}

Antonio Germane Alves Pinto trabalhou na concepção do estudo, na pesquisa de campo, na análise dos dados e na redação do artigo; Maria Augusta Vasconcelos Palácio e Aurylene Cordeiro Lôbo trabalharam na concepção e redação do artigo; e Maria Salete Bessa Jorge foi orientadora da pesquisa, participou da análise dos dados e redação do artigo. Todos os autores referem que não há conflitos de interesse.

Resumen Este estudio propone presentar las experiencias en el trabajo del agente comunitario de salud integrando las relaciones intersubjetivas en el territorio. La vinculación con la comunidad surge de su implicación con las mismas dificultades de la población que acompaña. El objetivo es estudiar las prácticas cotidianas vivenciadas por el agente comunitario de salud en el territorio de la Estrategia Salud de la Familia, haciendo énfasis en las relaciones comunitarias y los vínculos mantenidos. Investigación realizada con un enfoque cualitativo y desde una perspectiva crítica y reflexiva, en el municipio de Fortaleza, estado de Ceará, Brasil, durante el período de 2011 a 2013. Los participantes fueron 11 agentes comunitarios de salud y 22 usuarios de dos equipos de la Estrategia Salud de la Familia. Se utilizaron como técnicas de recolección de datos la entrevista semiestructurada, la observación sistemática y el grupo focal. Los datos se analizaron con las premisas de la hermenéutica crítica. Los resultados ponen de manifiesto que, en el trabajo cotidiano del agente comunitario de salud, las relaciones para el cuidado y promoción de la salud mantienen vínculos y afectos en los enfrentamientos comunitarios, demandas y necesidades comunitarias. La información y comunicación por medio del diálogo dan sentido y significado a las prácticas de salud y mejora de la calidad de vida. Se considera que los vínculos entre los usuarios y agentes comunitarios de salud son potentes y resolutivos.

Palabras clave agente comunitario de salud; salud de la familia; atención primaria de la salud; relaciones profesional-paciente.

\section{Notas}

${ }^{1}$ Universidade Regional do Cariri, Departamento de Enfermagem, Crato, Ceará, Brasil. <germanepinto@hotmail.com>

Correspondência: Rua Coronel Antônio Luiz, 1.161, Pimenta, CEP 63105-000, Crato, Ceará, Brasil. 


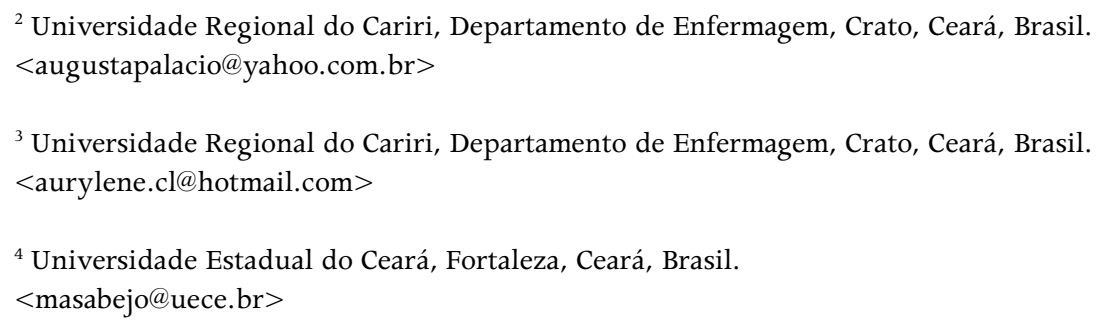

\section{Referências}

AYRES, José R. C. M. O cuidado, os modos de ser (do) humano e as práticas de saúde. Saúde e Sociedade, São Paulo, v. 13, n. 3, p. 16-29, dez. 2004.

BACKES, Dirce S. et al. Significado da atuação da equipe da Estratégia de Saúde da Família em uma comunidade socialmente vulnerável. Ciência \& Saúde Coletiva, Rio de Janeiro, v. 17, n. 5, p. 1.151-1.157, maio 2012.

BORNSTEIN, Vera J.; STOTZ, Eduardo N. O trabalho dos agentes comunitários de saúde: entre a mediação convencedora e a transformadora. Trabalho Educação e Saúde, Rio de Janeiro, v. 6, n. 3, p. 457-480, 2008.

BRASIL. Conselho Nacional de Saúde. Resolução n. 466, de 12 de dezembro de 2012. Brasília: Ministério da Saúde, 2012a.

BRASIL. Ministério da Saúde. Secretaria de Atenção à Saúde. Departamento da Atenção Básica. Evolução do credenciamento e implantação da estratégia Saúde da Família. Dados do estado do Ceará e capital. 2012b. Disponível em: <http://dab.saude.gov.br/ historico_cobertura_sf.php $>$. Acesso em: 10 fev. 2013.

CAPRARA, Andrea; RODRIGUES, Josiane. A relação assimétrica médico-paciente: repensando o vínculo terapêutico. Ciência \& Saúde Coletiva, Rio de Janeiro, v. 9, n. 1, p. 139-146, 2004.

CARDOSO, Andreia S.; NASCIMENTO, Marilene C. Comunicação no Programa Saúde da Família: o agente de saúde como elo integrador entre a equipe e a comunidade. Ciência \& Saúde Coletiva, Rio de Janeiro, v. 15, p. 1.509-1.520, jun. 2010. Suplemento 1.

COSTA, Elaine M.; FERREIRA, Danyege L. A. Percepções e motivações de agentes comunitários de saúde sobre o processo de trabalho em Teresina, Piauí. Trabalho, Educação e Saúde, Rio de Janeiro, v. 9, n. 3, p. 461-478, nov. 2011.

DE CARLI, Rafaela et al. Acolhimento e vínculo nas concepções e práticas dos agentes comunitários de saúde. Texto \& Contexto Enfermagem, Florianópolis, n. 23, v. 3, p. 626-632, jul.-set. 2014.

FAVORETO, Cesar. A. O. A prática clínica e o desenvolvimento do cuidado integral à saúde no contexto da atenção primária. Revista $A P S$, Juiz de Fora, v. 11, n. 1, p. 100-108, jan.-mar. 2008.

FERREIRA NETO, João L.; KIND, Luciana. Práticas grupais como dispositivo na promoção da saúde. Physis: Revista de Saúde Coletiva, Rio de Janeiro, v. 20, n. 4, p. 1.119-1.142, dez. 2010.

FLICK, Uwe. Introdução à pesquisa qualitativa. 3. ed. Porto Alegre: Artmed, 2009.

FONSECA, Angélica F. et al. Avaliação em saúde e repercussões no trabalho do agente comunitário de saúde. Texto \& Contexto Enfermagem, Florianópolis, v. 21, n. 3, p. 519-527, set. 2012 . 
FONSECA, Angélica F.; MOROSINI, Márcia V. G. C.; MENDONCA, Maria H. M. Atenção primária à saúde e o perfil social do trabalhador comunitário em perspectiva histórica. Trabalho, Educação e Saúde, Rio de Janeiro, v. 11, n. 3, p. 525-552, set. 2013.

FRACOLLI, Lislaine A.; ZOBOLI, Elma L. C. P. Descrição e análise do acolhimento: uma contribuição para o Programa de Saúde da Família. Revista da Escola de Enfermagem da USP, São Paulo, v. 38, n. 2, p. 143-151, jun. 2004.

GALAVOTE, Heletícia S. et al. Alegrias e tristezas no cotidiano de trabalho do agente comunitário de saúde: cenários de paixões e afetamentos. Interface: Comunicação, Saúde e Educação, Botucatu, v. 17, n. 46, p. 575-586, 2013.

GOMES, Márcia C. P. A; PINHEIRO, Roseni. Acolhimento e vínculo: práticas de integralidade na gestão do cuidado em saúde em grandes centros urbanos. Interface: Comunicação, Saúde e Educação, Botucatu, v. 9, n. 17, p. 287-301, ago. 2005.

GOMES, Mônica A.; PEREIRA, Maria L. D. Família em situação de vulnerabilidade social: uma questão de políticas públicas. Ciência \& Saúde Coletiva, Rio de Janeiro, v. 10, n. 2, p. 357-363, abr. 2005.

INSTITUTO BRASILEIRO DE GEOGRAFIA E ESTATÍSTICA. Informações sobre as cidades: Fortaleza. Brasília, 2014. Disponível em: <http:// www.ibge.gov.br/cidadesat/painel/painel.php?codmun=230440\#> . Acesso em: 10 fev. 2014.

JARDIM, Tatiane A.; LANCMAN, Selma. Aspectos subjetivos do morar e trabalhar na mesma comunidade: a realidade vivenciada pelo agente comunitário de saúde. Interface: Comunicação, Saúde, Educação, Botucatu , v. 13, n. 28, p. 123-135, mar. 2009.

JORGE, Maria S. B. et al. Promoção da Saúde Mental - Tecnologias do cuidado: vínculo, acolhimento, corresponsabilização e autonomia. Ciência \& Saúde Coletiva, Rio de Janeiro, v. 16, n.7, p. 3.051-3.060, jul. 2011.

LANZONI, Gabriela M. M. et al. Contexto da rede de relações e interações do agente comunitário de saúde. Cogitare Enfermagem, Curitiba, v. 18, n. 3, p. 439-45, jul./set. 2013.

MENEGUSSI, Juliana M.; OGATA, Márcia N.; ROSALINI, Maria H. P. O agente comunitário de saúde como morador, trabalhador e usuário em São Carlos, São Paulo. Trabalho, Educação e Saúde, Rio de Janeiro, v. 12, n. 1, p. 87-106, abr. 2014.

MINAYO, Maria C. S. O desafio do conhecimento: pesquisa qualitativa em saúde. 14 ed. São Paulo: Hucitec, 2014.

PEREIRA, Iara C.; OLIVEIRA, Maria A. C. $\mathrm{O}$ trabalho do agente comunitário na promoção da saúde: revisão integrativa da literatura. Revista Brasileira de Enfermagem, Brasília, n. 66, v. 3, p. 412-419, maio/jun. 2013.

PINTO, Antonio G. A.; JORGE, Maria S. B. Prática clínica em saúde mental no cotidiano do Centro de Atenção Psicossocial. Cogitare Enfermagem, Curitiba, v.14, n. 2, p. 217-26, 2009.

SANTOS, Adriano M. et al. Vínculo e autonomia na prática de saúde bucal no Programa Saúde da Família. Revista de Saúde Pública, São Paulo, v. 42, n. 3, p. 464-470, jun. 2008.

SANTOS, Adriano. M.; ASSIS, Marluce M. A. Da fragmentação à integralidade: construindo e (des)construindo a prática de saúde bucal no Programa de Saúde da Família (PSF) de Alagoinhas, BA. Ciência \& Saúde Coletiva, Rio de Janeiro, v. 11, n. 1, p. 53-61, mar. 2006.

SCHIMITH, Maria D.; LIMA, Maria A. D. $\mathrm{S}$. Acolhimento e vínculo em uma equipe do Programa Saúde da Família. Cadernos de Saúde Pública, Rio de Janeiro, v. 20, n. 6, p. 1.487-1.494, nov.-dez. 2004.

VIEGAS, Selma M. F.; PENNA, Cláudia M. M. $\mathrm{O}$ vínculo como diretriz para a construção da integralidade na Estratégia Saúde da Família. Revista da Rede de Enfermagem do Nordeste, Fortaleza, n. 13, v. 2, p. 375-385, 2012.

Recebido em 27/03/2016

Aprovado em 20/07/2016 